\title{
S- 5-4 Atherosclerosis from a Viewpoint of Arterial Wall Cell Function: Relation to Vitamin E
}

\author{
N.MorisAKI, K.YoKOTE, and Y.SAITO
}

The Second Department of Internal Medicine, School of Medicine, Chiba University 1-8-1 Inohana, Chiba 280(Japan)

Many phenomena are observed in atheromatous lesions such as endothelial cell (EC) injury, platelet aggregation, invasion of circulating blood monocytes(M0) into the subendothelial space, foam cell formation, migation of medial smooth muscle cells (SMC) to the intima, and proliferation there. These phenomena occur through metabolism in and interaction between cells which consist thickened intima. This paper will present data on vitamin $E$ effects on some of these key events in the formation of atheromatous lesions.

\section{I . MONOCYTES ADHESION TO EC}

Foam cell formation is a well known phenomenon in atheromatous lesions. An origin of foam cells is macrophages $(\mathbb{\phi} \phi)$ derived from circulating blood $\mathbf{M} 0$. Invasion of $\mathbb{M} 0$ into the subendothelial space is a very early event in the formation of fatty streak in hypercholesterolemia. The mechanism of this invasion is not known well but recently it was reported that adhesion of 0 to $\mathrm{EC}$ is the earliest event for this invasion. Moreover, vascular cellular adhesion molecule(VCAM)-1 was suggested to be a candidate for the adhesion molecule in the atheromatous lesions[1]. We found that activation of EC through stimulation of phosphlipase $A_{2}$ in $\mathrm{EC}$ is an important mechanism of the expression of the adhesion molecule. As vitamin $\mathrm{E}$ inhibited phosphlipase $\mathrm{A}_{2}$ in platelets, we studied vitamin $\mathrm{E}$ effect on the adhesion of Mo to $\mathrm{EC}$.

Various cytokines, which stimulated phospholipase $A_{2}$ activities in EC such as interleukin-1(IL-1) ( $\alpha \& \beta$ ), tumor necrosis factor, lipopolysaccharide, and TPA, increased adhesion of THP-1 cells to human umbilical cord vein EC by 1.5 to 2 fold over the control when EC were incubated with optimal doses of these factors for $18 \mathrm{~h}$. Treatment with venom phospolipase $\mathrm{A}_{2}$ of $\mathrm{EC}$ also increased the adhesion. Moreover, inhibitors of phosphlipase $\mathrm{A}_{2}$ such as quercetin, mepacrine, and $\mathrm{p}$ bromophenacyl-bromide decreased the adhesion of 10 to $\mathrm{EC}$. These data indicated that activation of phospholipase $\mathrm{A}_{2}$ was a trigger of the expression of adhesion molecule. Vitamin $\mathrm{E}$ was added to the culture $6 \mathrm{~h}$ prior to the stimulation with $\mathrm{IL}-1 \beta(2 \mathrm{u} / \mathrm{ml})$, but $1-50 \mu$ vitamin $\mathrm{E}$ had no effect on the adhesion of 0 to $\mathrm{EC}$.

II. ENZYME ACTIVITIES IN THE ARTERIAL WALL OF TOCOPHEROL DEFICIENT RATS Lipid metabolism in the arterial wall is closely related to foam cell formation. Usually normal diets contain significant amount of vitamin $E$ and further addition of vitamin $\mathbb{E}$ may have little effect on the biology of arterial 
walls. Thus we compared tocopherol deficient animals(TD) with tocopherol supplement animals(TS) to clarify the vitamin $E$ effects on the lipid metabolism in the arterial wall.

Wistar male rats were fed either tocopherol deficient diet or tocopherol supplement diet for 4 months. In this condition serum lipid levels were not so different between two groups except slightly higher triglyceride level in TD. serum tocopherol level was significantly higher in TS than in TD(0.60 \pm 0.23 vs $0.11 \pm 0.05, \mathrm{mg} / \mathrm{d} 1, \mathrm{p}<0.005)$. Lipid peroxide content was significantly higher in TD than in TS $(29.8 \pm 3.7,18.8 \pm 6.8, \mathrm{nmol} / \mathrm{mg}$ protein, $\mathrm{p}<0.025)$. No atheromatous lesions were observed macroscopically.

Table 1 summarized enzyme activities concerning lipid metabolism in the arterial walls of both groups. A11 enzyme activities were decreased in TD except choline phosphotrsansferase. However, the decrease in activities was most prominent in lysosomal enzymes such as acid cholesterol esterase and lipase. The decrease in activities of most enzymes suggested that enzyme proteins themselves were impaired by lipid peroxides. The increase in the activity of cholinephospho -trasnsferase may be due to induction of the enzyme to repair injured membranes. The most important finding was the marked decrease in the lysosomal enzymes which indicates that cholesterol ester may accumulate as deposits of a lysosomal origin. The reason why lysosomal enzymes were more impaired is not clear but one possibility is that exogenous lipoproteins which contain lipid peroxides may have been taken up and first transported to lysosomes and therefore those may have most strongly affected lysosomal enzymes.

Table 1. Jipid metabolism in the aorta of rats on tocopherol deficient diet

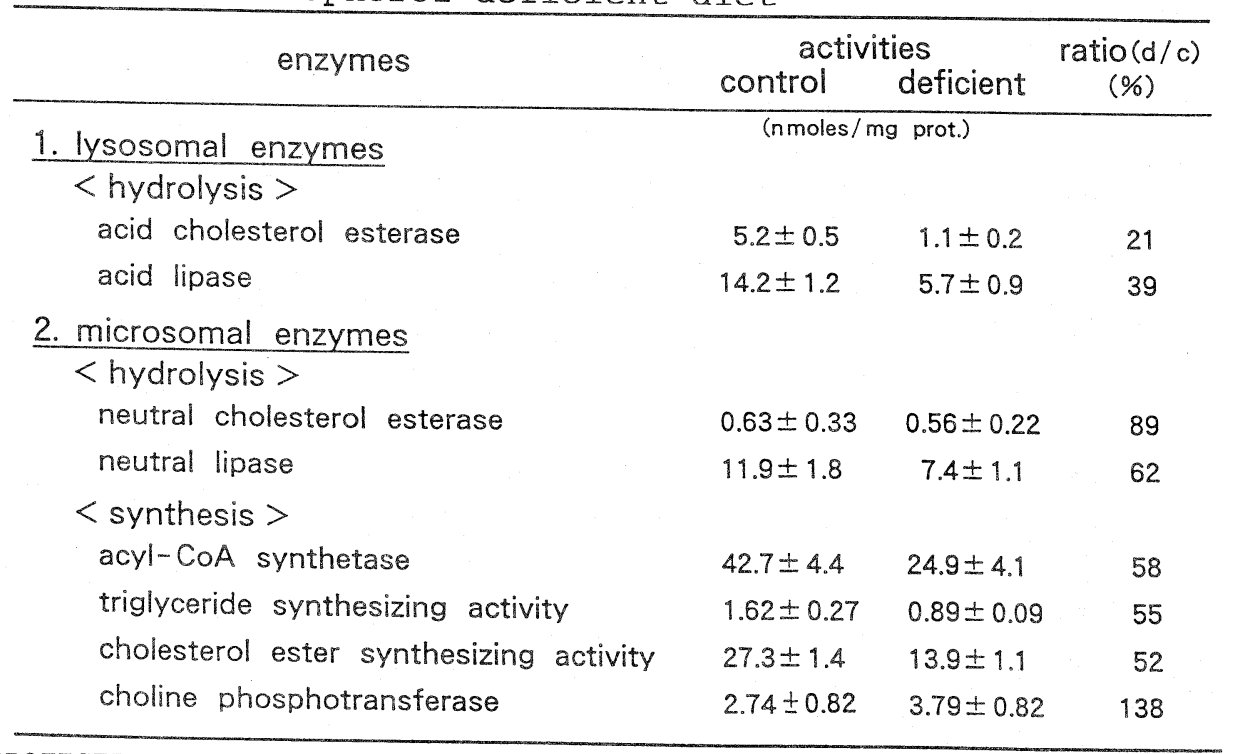

III. PROTECTIVE EFFECT OF VITAMIN E ON CHOLESTEROL ESTERASE

As vitamin $\mathbb{E}$ was suggested to protect enzyme proteins of lysosomal enzymes from lipid peroxides, we next tried to prove it in vitro.

$\left[{ }^{3} \mathrm{H}\right]$ Cholesterol ester-labeled LDL or acetylated LDL were incubated with rat aortas or rat peritoneal $\$ \phi$ for $3 \mathrm{~h}$, respectively, and released labeled free fatty acid was measured. When either rat aortas or $\phi$ or lipoproteins were preincubated with $10 \mu \mathrm{W}$ vitamin $\mathrm{E}$, the release of free fatty acid was significantly increased compared to the controls by 1.33 fold in aortas and 1.18 fold 
in $\boldsymbol{M} \phi$, indicating that lysosomal cholesterol esterase activities were increased. These data suggested that vitamin $\mathrm{E}$ protected the enzyme protein from lipid peroxides.

\section{EXPRESSION OF SCAVENGER PATHWAY IN SMC}

The origin of foam cells is not only M $\phi$ but also SHC. The mechanism of foam cell formation from SWC is not known well. The LDL pathway does not explain cholesterol ester accumulation in SMC because LDL receptor activity and therefore LDL uptake are strictly regulated by intracellular cholesterol content to keep it at the same level. We reported that SMC cultured from arteriosclerotic intima(intimal SMC) expressed the scavenger pathway whereas SMC cultured from normal media(medial SMC) did not[2]. Expression of scavenger pathway may explain the mechanism of foam cell formation because the uptake of denatured LDL is not regulated by intracellular cholesterol. As the in vivo mechanism of the expression of scavenger pathway is unclear, next the mechanism was studied in vi tro.

Confluent cultured rabbit aortic medial SMC were incubated with acetylated LDLlabeled either with a fluorescence(DiI-a-LDL) or iodine-125(125-I-a-LDL) for $12 \mathrm{~h}$ or $24 \mathrm{~h}$, respectively. Some SMC were preincubated with growth factors and cytokines [platelet derived growth factor(PDGF), tumor necrosis factor(TNF), TPA , fibroblast growth factor, somatomedin C, transforming growth factor- $\beta$, interleukin-1 and epidermal growth factor] for $24 \mathrm{~h}$ prior to this incubation.

As shown in Fig. 1, untreated medial SWC did not degradate 125-I-a-LDL at a11. Preincubation of medial SUC with $10^{-8} \mathrm{TPA}, 10 \mathrm{ng} / \mathrm{ml}$ of PDGF-AB or BB, and $1 \mathrm{u} / \mathrm{m} 1$ of TNF resulted in degradation activity of 125-a-LDL, TPA effect being most remarkable. PDGF-AA and other factors had no effect on this expression of the

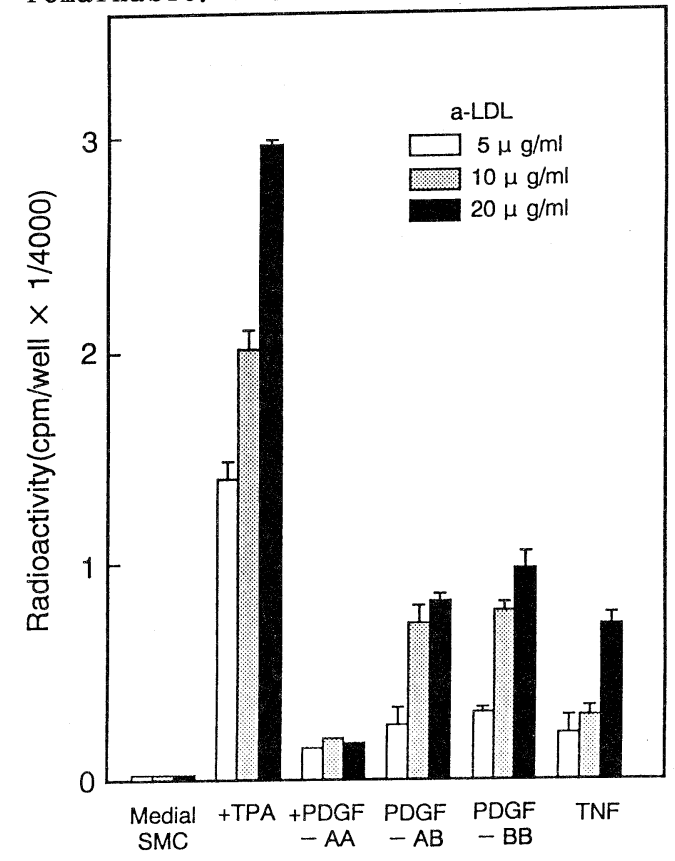

Fig.1. Degradation of a-LDL in SMC treated with cytokines

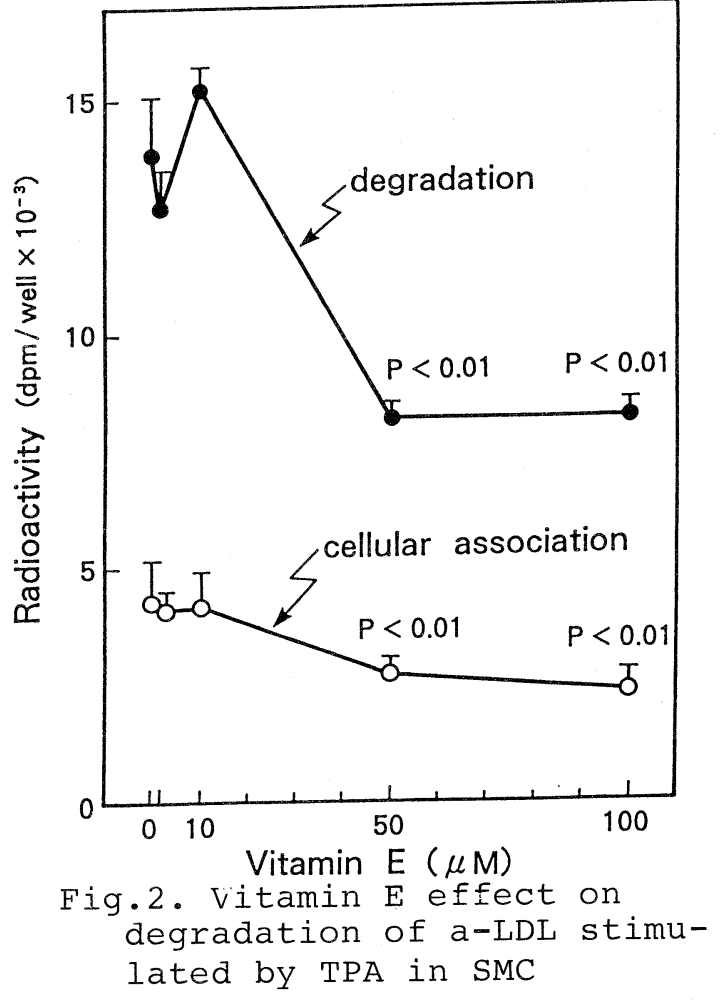


scavenger pathways. These data were confirmed by fluorescent microscopy of medial SMC incubated with $5 \mu \mathrm{g} / \mathrm{ml}$ of DiI-a-LDL. Next effect of vitamin $\mathrm{E}$ on the expression of scavenger pathway was studied in vitro.

Confluent medial SHC were treated with $10^{-8}$ TPA in the presence of $1-100 \mu$ of vitamin $\mathrm{E}$ (vitamin $\mathrm{E}$ was added to the culture $1 \mathrm{~h}$ prior to TPA). Then $10 \mu \mathrm{g} / \mathrm{m} 1$ of $125-\mathrm{I}-\mathrm{a}-\mathrm{LDL}$ was incubated with the cells for $24 \mathrm{~h}$ at $37{ }^{\circ} \mathrm{C}$ and degradation and cellular association activities were measured. Vitamin $\mathrm{E}$ at 1-10 $\mu$ had no effect but at $50 \mu$ and higher decreased the activities by $50 \%$.

\section{SMC PROLIFERATION AND VITAMIN E}

We reported that intracellular lipid peroxidation derived from polyunsatulated fatty acids inhibited cell proliferation of many cell lines including aortic SMC(3). The inhibitory effects of polyunsaturated fatty acids were roughly dependent on the number of double bonds. Many antioxidants including vitamin $\mathrm{E}$ inhibited intracellular lipid peroxidation from polyunsaturated fatty acids. All antioxidants which inhibited the lipid peroxidation enhanced cell proliferation of SWC. $1-10 \mu$ of Vitamin $E$ was enough to inhibit lipid peroxidation and to enhance cell proliferation. These results indicated that antioxidative effect is the mechanism of enhancement of cell proliferation by vitamin E. On the other hand high concentration of vitamin E such as $50-100 \mu$ I inhibited cell proliferation of SMC(4). The inhibitory effect was suggested to be through inhibition of protein kinase $\mathrm{C}$ which is closely related to cell proliferation. These bifunctional effects of vitamin $\mathrm{E}$ are shown in Fig. 3.

\section{SUMHARY}

Vitamin $\mathrm{E}$ affects many key events in atheromatous lesions. Inhibition of EC injury and platelet aggregation was already reported. Foam cell formation must be inhibited according to the data presented by us and other speakers. However, effects on cell proliferation of SWC are paradoxical. The in vivo effects will be dependent on the effective concentration of vitamin $\mathrm{E}$ in the loci.

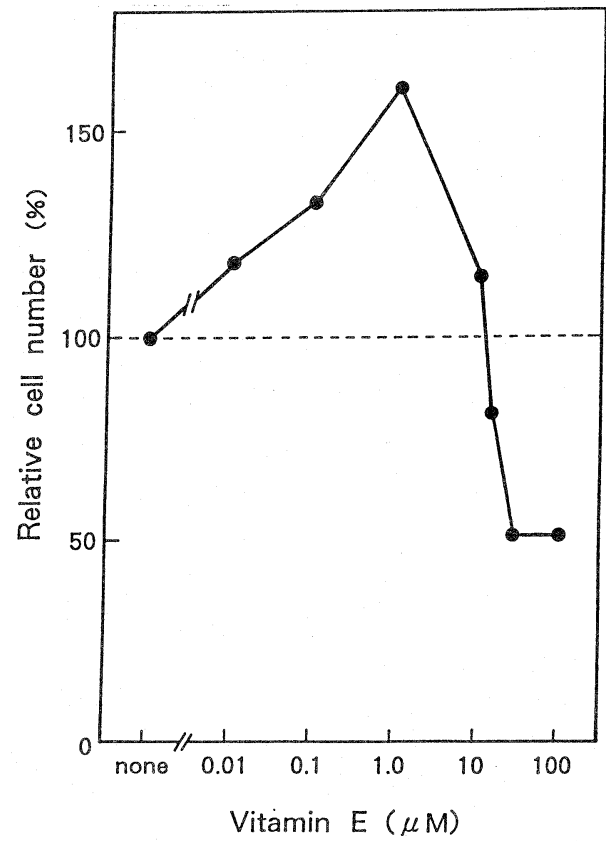

Fig.3. Vitamin E effect on cell proliferation stimulated by FBS

References

[1] Cybulski, M. I. and Gimbrone, M. A. (1991) Science 251:788-791.

[2] Saito, Y. et al. (1988) Atherosclerosis 69:161-164.

[3] Cornwe11, D. G. and Morisaki, N. (1984): In Free radicals in biology VI, ed. by Pryor, W. A., pp. 95-148, Academic Press, Inc., 0rland.

[4] Boscoboinik, D. et al. (1991) J. Biol. Chem. 266:6188-6194. 